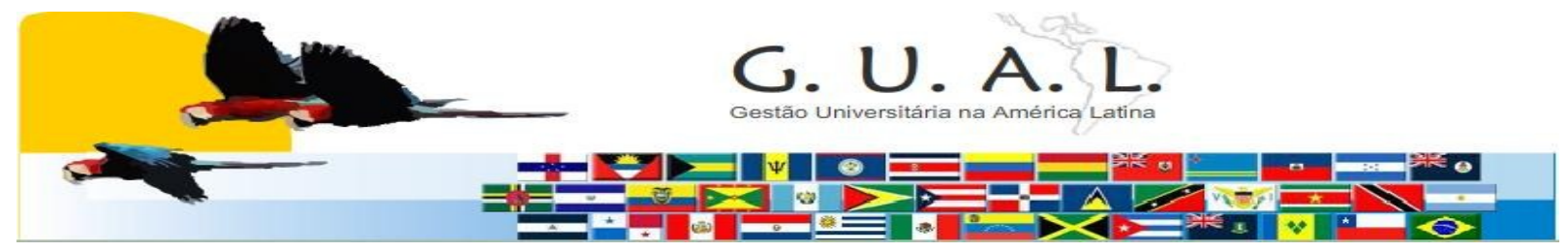

ISSN 1983-4535

\title{
AVALIAÇÃO DO PROCESSO DE INGRESSO DOS SERVIDORES TÉCNICO-ADMINISTRATIVOS DA UNIVERSIDADE FEDERAL DE SANTA CATARINA - UFSC
}

\author{
Adão de Oliveira Filho, Especialista \\ Universidade Federal de Santa Catarina - UFSC \\ adao12br@yahoo.com.br \\ Daniela Quadros, Especialista \\ Universidade Federal de Santa Catarina - UFSC \\ danielaquadros@yahoo.com.br \\ Rogério da Silva Nunes, Doutor \\ Universidade Federal de Santa Catarina - UFSC \\ rogerionunes@cse.ufsc.br
}

\begin{abstract}
RESUMO
$\mathrm{O}$ artigo tem o objetivo de avaliar o processo de ingresso dos servidores técnicoadministrativos da Universidade Federal de Santa Catarina- UFSC, em relação ao curso de Iniciação as Atividades Administrativas desde o seu início em 2008. Através de um estudo de caso de natureza descritiva e qualitativa com os servidores recém-contratados que participaram deste curso no período de 2008 a 2011 e entrevista com a Diretora da Divisão de Capacitação e Afastamento para Formação da Pró-Reitoria de Desenvolvimento Humano e Social da UFSC - DCAF/PRDHS, concluiu-se que os resultados são positivos no quesito referente a crescimento pessoal e conhecimento da Instituição, mas deixam a desejar no que diz respeito a uma política de gestão de capacitação em relação aos recém-contratados, quando não inclui assuntos e atividades inerentes à rotina administrativa, de acordo com solicitação dos técnicos e das chefias. Apesar de haver uma política de gestão de pessoal na área de capacitação alinhada aos cursos oferecidos, o processo ainda carece de uma maior estrutura, uma vez que não há uma avaliação sobre a aplicação prática dos cursos no ambiente institucional.
\end{abstract}

Palavras-chave: Capacitação de servidores. Política de gestão de pessoas. Recursos humanos. 


\section{INTRODUÇÃO}

A implantação do Plano de Cargos e Carreira dos Servidores Técnico-Administrativos da Educação, através a Lei $\mathrm{n}^{\circ}$. 11.091, de 12 de Janeiro de 2005, atendendo às antigas reivindicações dos servidores das Instituições Federais de Ensino Superior, trouxe entre outras inovações, ações para a formação profissional, possibilitando a implantação de políticas de capacitação, visando à qualificação do servidor.

O Programa de Capacitação e Desenvolvimento estabelecido no artigo $7^{\circ}$ do Decreto $n^{\circ}$ $5825 / 2006$, tem contribuído para esta qualificação ao enumerar como objetivos a contribuição para o desenvolvimento do servidor, como profissional e cidadão, a capacitação do servidor para o desenvolvimento de ações de gestão, e para o exercício de atividades de forma articulada com a função social da Instituição Federal de Ensino - IFE.

A iniciação ao serviço público contemplada no parágrafo único deste mesmo artigo, foco deste estudo, é uma das linhas de desenvolvimento deste programa que objetiva possibilitar aos técnico-administrativos conhecimento da função do Estado, das especificidades do serviço público, da missão da IFE, da conduta do servidor público e sua integração ao ambiente institucional.

As universidades constituem-se em um ambiente propício para o desenvolvimento de programas de aperfeiçoamento e atualização, visto que o quadro de pessoal é composto por uma grande diversidade de especialistas tanto no corpo docente como servidores técnicoadministrativos. $\mathrm{O}$ fato de a Universidade nem sempre conseguir motivar seus servidores no sentido de aperfeiçoamento deve-se ao fato de que este está ligado à carreira e a carreira, por sua vez, principalmente no caso das universidades, é pouco motivadora, por motivos principalmente, de política salarial defasada. (GRILLO, 1990).

Com o incentivo do Governo Federal para aperfeiçoamento e capacitação dos técnicoadministrativos das IFES, a procura dos Cursos de aperfeiçoamento (especialização, mestrado e doutorado), e cursos de capacitação aumentou significativamente. Estes cursos, principalmente os de capacitação que são oferecidos pela Instituição, possibilitam não só o aperfeiçoamento destes servidores em suas atividades, como também, o avanço de referência nos cargos através do acumulo de carga horária dos módulos

Este artigo tem o objetivo de avaliar o processo de ingresso dos servidores técnicoadministrativos quanto aos cursos de iniciação aos recém-contratados e para isso se utilizará 
de pesquisa exploratória e descritiva, utilizando-se de fontes primárias e secundárias, com dados coletados através de revisão bibliográfica, questionário aplicado aos servidores e entrevista estruturada à Diretora da Divisão de Capacitação e Afastamento para Formação DCAF/PRDHS.

Junto ao Setor de Capacitação da UFSC foram levantados dados relativos ao número de servidores e outras informações relativas ao perfil destes técnicos, considerados relevantes para a pesquisa.

\section{POLÍTICA DE GESTÃo de PESSOAS}

O sucesso e o fracasso de qualquer organização e/ou instituição está associado ao resultado do trabalho de um grupo de pessoas. Para Robert W. Woodruff, ex-diretor executivo da Coca-Cola, "são as pessoas e suas reações que fazem as empresas serem bem-sucedidas ou quebrar”. (CRISÓSTOMO, 2008)

Segundo Tachizawa (2001) e Moscovici (2003), qualquer organização que pretenda obter sucesso deste resultado, deve investir entre outros fatores, principalmente no desenvolvimento de pessoas, através da formação de equipes mais qualificadas e de gestores capazes de criar ambientes ideais para que seus subordinados dêem o melhor de si, ou seja, numa política de gestão de pessoas.

Moscovici (2003) considera que o desenvolvimento de pessoas denominado por ele como desenvolvimento interpessoal passa a ser uma necessidade de desenvolvimento organizacional e social. Sendo a pessoa o subsistema principal da organização, o sistema tecnológico e o macro sistema social dependerão do funcionamento efetivo do primeiro, em seu contexto habitual - o grupo humano. Este desenvolvimento apresenta três diferentes formas. São elas:

1- A nível individual, o desenvolvimento interpessoal e intrapessoal, caminham juntos, estudam-se complexidade da motivação individual, o comportamento dentro do ambiente de trabalho, busca-se desenvolver conhecimento técnico e autoconhecimento;

2- A nível grupal desenvolve-se as habilidade interpessoais e grupais, ou seja, explora-se os objetivos e motivações comuns ao grupo, comunicação, administração de conflitos, autoridade e liderança;

3- A nível organizacional, focaliza-se a organização com um todo, trabalhando o desenvolvimento de equipes, feedback, motivações pessoais e organizacional, em uma visão macro de conflitos e objetivos a serem sanados e traçados, respectivamente.

Rev. GUAL., Florianópolis, Edição especial 2011, p.274-288. 
Para Campos e Verni (2006), todo desenvolvimento interno depende de pessoas, e estas precisam ser valorizadas, cabendo aos gestores universitários identificarem as peculiaridades advindas das relações humanas existentes nas instituições de ensino superior. De fato, a grande dificuldade das IFES ainda são as questões ligadas à remuneração, motivação, desenvolvimento e reconhecimento das pessoas (SOUZA, 2009).

Para Marconi (2004) a política de gestão de pessoas dentro do setor público corresponde ao alcance do perfil desejado para a força de trabalho e sua atuação de forma motivada e eficiente, em um modelo de gestão que vise o alcance de resultados e o atendimento satisfatório ao cidadão.

Souza e Kobiyama (2010) consideram o estabelecimento de uma política de gestão de pessoas nas organizações fundamental para a implementação do plano estratégico da organização. E especialmente no ambiente universitário, onde novas formas de ensinar e novas linhas de pesquisa e extensão podem ser desenvolvidas, o pensar sobre uma política de gestão de pessoas para o seu meio acadêmico e administrativo deve ser, de fato, uma prioridade.

De acordo com Grillo (2001) para que as Universidades alcancem um grau de perfeição, a carreira de seus servidores deve privilegiar, sobretudo, o mérito tanto de professores e pesquisadores, como de técnicos e administradores, no exercício de suas respectivas atividades. O que significa que ao invés de dar ênfase ao tempo de serviço, maior atenção deve ser dada ao processo de aperfeiçoamento contínuo, à produção e publicação de trabalhos técnicos e científicos, e à verificação periódica do desempenho.

Para Dutra (2002), a efetividade da gestão estratégica de pessoas está relacionada à clareza por parte da organização sobre o que ela espera das pessoas.

A universidade tem um compromisso com a sua força de trabalho, isto é, compromisso de formar recursos humanos competentes, eficientes, para que esses estejam capacitados e preparados para contribuírem nos processos decisórios do seu ambiente de trabalho (CORADINI, 2011).

Nas Instituições Federais de Ensino Superior, a política de gestão de pessoas é fundamentada na Lei $\mathrm{n}^{\mathrm{o}} 11.091 / 2005$ e no Decreto $\mathrm{n}^{\mathrm{o}} 5.825 / 2006$, que ampliaram as possibilidades de desenvolvimento profissional dos servidores integrantes do Plano de Carreira, e, por conseguinte, a sua inserção no desenvolvimento organizacional, entendido 
como crescimento do servidor enquanto sujeito no processo de trabalho e na carreira, através da participação no planejamento, avaliação institucional e de desempenho e da capacitação necessários ao cumprimento dos objetivos institucionais (CEFET/RJ, 2005).

Para Luck (2001:96) a realização de programas de capacitação no trabalho "é um elemento importante para qualquer programa que vise ao aperfeiçoamento educacional e à melhoria da qualidade do ensino".

A instituição precisa construir uma cultura onde prevaleça a gestão participativa, que integre os interessados de forma a buscarem melhorias para o ensino e para seu bem estar. Portanto, as instituições de ensino que almejam ter uma maior qualidade nos serviços prestados precisam ter a concepção de que somente conseguirão essa qualidade capacitando seus colaboradores; em contrapartida terão trabalhadores mais participativos, comprometidos e muito mais motivados para desenvolverem suas atividades (CORADINI, 2011).

Olivier (2001) entende que as normas de recursos humanos nas Instituições Federais de Ensino Superior são estabelecidas por técnicos e professores, que ocupam cargos de confiança. Ocorre que estas pessoas, desconhecem requisitos técnicos para gerenciar questões inerentes aos recursos humanos.

Pacheco (2002) entende que a partir do momento em que a área de recursos humanos se posicionarem como agente de mudança e entender que o seu propósito maior é apoiar o desenvolvimento de pessoas para que a instituição alcance seus resultados, a capacitação poderá tomar novo impulso e maior eficácia.

\subsection{Capacitação e treinamento}

Na visão de Robbins (2002) a Universidade tem o compromisso em capacitar os seus colaboradores para que possam desempenhar com eficiência e eficácia suas funções. E acrescenta:

Os administradores, bem como muitos funcionários que realizam tarefas não rotineiras, precisam solucionar problemas em seu local de trabalho. Quando essas habilidades são exigidas, mas o funcionário não as possui muito desenvolvidas, ele pode participar de treinamento para solução de problemas. Isso inclui atividades para desenvolver sua lógica, raciocínio e habilidade de definição de problemas, além de sua capacidade de identificação de causas, desenvolvimento de alternativas, análise de alternativas e seleção de soluções (ROBBINS, 2002, p. 469).

Rev. GUAL., Florianópolis, Edição especial 2011, p.274-288. 
As novas exigências advindas de mudanças na gestão pública tendem a demandar das universidades a criação de mecanismos para o incentivo e a valorização de seus recursos humanos, por meio do desenvolvimento de ações de capacitação, direcionadas para a democratização do saber no âmbito institucional (MARQUES, 2002).

Nesta concepção Pacheco (2002) afirma que a maior efetividade no uso de recursos destinados à capacitação depende, também, de um realinhamento estratégico das áreas de recursos humanos nas organizações públicas.

No entender de Magalhães et. al (2010) o que se verifica, atualmente, é que o processo de treinamento precisa desenvolver competências nas pessoas, no sentido de tornarem-se mais produtivas e contribuir para a organização. Por essa razão, quando se refere à capacitação de pessoas, a tendência é falar em desenvolvimento de pessoas ou educação no trabalho. Assim, desenvolver pessoas significa: oferecer-lhes a formação básica para que transformem antigos hábitos, desenvolvam atitudes e capacitem-se para melhorar seus conhecimentos, buscando tornarem-se melhores na realização do trabalho.

$\mathrm{Na}$ concepção de Souza (2009) faltam programas de educação permanente para docentes e técnicos. Considera o autor, que existem esforços para se capacitar as pessoas, mas utilizam-se métodos que nem sempre atendem às necessidades das IFES. Além disso, não se questiona muito sobre o desempenho profissional e há, também, a acomodação por parte de alguns servidores docentes e técnico-administrativos.

A falta de uma política consistente de pessoal faz com que esses servidores busquem formação muito mais por interesses individuais, do que institucionais. Além disso, às vezes, os programas de capacitação existentes se afastam das reais necessidades da universidade. Há casos em que os servidores não demonstram interesse em freqüentar os cursos que são oferecidos (SOUZA, 2009).

A melhoria da qualidade da prestação dos serviços públicos passa pela modernização da área de RH, revisando os processos de trabalho e informatização das suas rotinas e, principalmente, pela capacitação dos servidores. Necessário se faz repensar o conceito que se tem do ser humano no espaço das organizações (MENEGASSO e SALM 2001).

Rev. GUAL., Florianópolis, Edição especial 2011, p.274-288. 


\title{
2.2 O programa de capacitação da UFSC
}

A Universidade Federal de Santa Catarina - UFSC, com base nos Decretos $\mathrm{n}^{\mathrm{o}} \mathrm{s}$. 94.664/87, 5.707/2006 e 5.825/2006 e de conformidade com a Lei $\mathrm{n}^{\mathrm{o}}$. 11.091/2005 instituiu a Portaria Normativa $n^{\circ}$. 017/GR/2008, com normas de funcionamento dos cursos de capacitação profissional oferecidos pelo Departamento de Desenvolvimento de Potencialização de Pessoas da Pró-Reitoria de Desenvolvimento Humano e Social DDPP/PRDHS, destinados aos servidores docentes e técnico-administrativos da UFSC.

Os cursos de capacitação são basicamente atividades de aprendizagem que procuram desenvolver as competências institucionais por meio das competências individuais dos servidores, cuja necessidade tenha sido detectada pela Universidade (Portaria Normativa $\mathrm{n}^{\circ}$. 017/GR/2008).

O conteúdo programático do curso de iniciação às atividades técnico-administrativas da UFSC - Universidade Federal de Santa Catarina, de acordo com depoimento da Diretora da Divisão de Capacitação e Afastamento para Formação - DCAF da UFSC vem de encontro ao que contempla o art. $7^{\circ}$, Parágrafo Único, I do Decreto $\mathrm{n}^{\circ} 5.825 / 2006$, in verbis:

\begin{abstract}
Art. $7^{\circ}(\ldots)$
Parágrafo único. O Programa de Capacitação e Aperfeiçoamento deverá ser implementado nas seguintes linhas de desenvolvimento:

I - iniciação ao serviço público: visa ao conhecimento da função do Estado, das especificidades do serviço público, da missão da IFE e da conduta do servidor público e sua integração no ambiente institucional. ${ }^{1}$
\end{abstract}

No que tange às especificidades do serviço público, conforme informações do Setor de Capacitação da UFSC são oferecidos cursos de acordo com a transcrição das necessidades, solicitadas pelos servidores técnico-administrativos e respectivas chefias, em formulários específicos. No entanto, não se verifica uma continuidade do processo e/ou a integração com outros processos independentes.

Olivier (2001) menciona este procedimento alegando que as demais fases do processo que envolve o planejamento das ações de treinamento, a implementação e a avaliação, não são

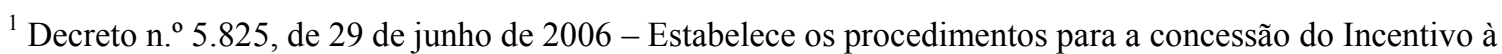
Qualificação e para a efetivação do enquadramento por nível de capacitação dos servidores integrantes do Plano de Carreira dos Cargos Técnico-Administrativos em Educação, instituído pela Lei n. ${ }^{\circ} 11.091$, de 12 de janeiro de 2005.
}

Rev. GUAL., Florianópolis, Edição especial 2011, p.274-288. 
facilmente identificadas, até mesmo porque algumas costumam não existir.

\section{METODOLOGIA}

A pesquisa realizada tem natureza exploratória e descritiva. Segundo Gil (1994:70) pesquisa exploratória é aquela cujo objetivo se concentra em conhecer melhor o objeto a ser investigado, "pode-se dizer que estas pesquisas têm como objetivo principal o aprimoramento de idéias ou a descoberta de intuições”. Para Vergara (2005), a pesquisa descritiva expõe características de determinada população, podendo estabelecer associação entre variáveis.

É um estudo de caso que conforme Gil (1999) possibilita investigar o fenômeno com maior profundidade dentro do seu contexto, não interferindo em suas características significativas.

A população alvo da pesquisa são os servidores Técnico-Administrativos recém contratados que realizaram cursos de Iniciação às atividades Técnico-Administrativas da UFSC no período de 2008 ao primeiro semestre de 2011, que segundo dado do Setor de Capacitação perfaz um total de 307 servidores. Destes, 133 são ocupantes de cargos de nível médio e 174 ocupantes de cargos de nível superior.

Foi enviado questionário por email para todos os 307 servidores, sendo que 57 responderam. Faz parte da pesquisa também, entrevista realizada com a Diretora da Divisão de Capacitação e Afastamento para Formação - DCAF da UFSC.

Os dados foram tratados e interpretados pela abordagem qualitativa, que segundo Godoy (1995), não numera e/ou mede os fatos estudados, mas explora e revelam fenômenos sobre pessoas, lugares e processos interativos. O instrumento de coleta de dados é um questionário fechado e aberto composto por 15 assertivas, divididos em três blocos: Dados de Identificação, Ambiente de trabalho e Curso(s) Oferecido(s).

Os blocos sobre "Ambiente de Trabalho" e "Curso(s) Oferecido(s)" são compostos por assertivas onde são oferecidas afirmações sobre o objeto pesquisado, utilizando o procedimento da escala Likert. Nesta escala as questões são organizadas de forma a permitir que os respondentes não só respondam se concordam como também informem o seu grau de concordância ou discordância, atribuindo-se valores às respostas.

Ao bloco "Ambiente de Trabalho", que conta ainda com uma questão aberta sobre a necessidade de um curso específico, foi atribuída uma escala de 1 a 4 para: regular, 
satisfatório, bom e ótimo e; discordo totalmente, discordo parcialmente, concordo parcialmente e concordo totalmente, respectivamente. Já para o bloco Curso(s) Oferecido(s), utilizou-se escala de 1 a 5, na seqüência, para: nenhum, 1 curso, 2 cursos, 3 cursos, acima de 3 cursos e; 1 a 4 para discordo totalmente, discordo parcialmente, concordo parcialmente e concordo totalmente.

Para Pereira (2001) o sucesso da escala de Likert consiste no fato de que ela tem a sensibilidade de recuperar conceitos aristotélicos da manifestação de qualidades: reconhece a oposição entre contrários, reconhece gradiente, e reconhece situação intermediária, dentro de uma análise qualitativa.

\section{RESULTADOS}

Os servidores Técnico-Administrativos expressaram através das 15 assertivas a sua impressão a respeito do processo de capacitação e treinamento dos servidores recém admitidos da UFSC.

Através de análise documental junto ao Setor de Capacitação, observou-se que o perfil destes técnicos tem evoluído nestes últimos anos. A formação acadêmica da maioria dos entrevistados é superior à solicitada para o preenchimento dos cargos que ocupam. Dos 307 técnicos participantes do curso de iniciação, detectou-se que dos 133 ocupantes de cargo de nível médio, $53 \%$ possuem curso superior, $13 \%$ curso de especialização e $3 \%$ dividem-se entre cursos de mestrado e doutorado. No que tange aos 174 servidores que ocupam cargos de nível superior, $26 \%$ têm curso de especialização, $15 \%$ curso de mestrado e $1 \%$ curso de doutorado.

Com relação a faixa etária, 94\% destes servidores têm idade na faixa compreendida entre 20 a 40 anos.

Dos 57 servidores respondentes, $92 \%$ consideram que o curso de Iniciação às Atividades Administrativas, ministrado pela Universidade, tem utilidade para a Instituição e auxiliam no desenvolvimento do trabalho, havendo uma melhora no resultado das atividades praticadas no ambiente institucional.

Analisando o bloco de questões acerca do Ambiente de Trabalho, detectou-se que 77\% dos servidores técnico-administrativos consideram a adaptação ao novo ambiente boa ou ótima e deste universo $84 \%$ acha que esta adaptação deveu-se ao Curso de Iniciação. 
Com relação ao item Curso(s) Oferecido(s), 95\% dos respondentes consideram necessário que haja cursos voltados para suas áreas específicas de atuação. A maioria dos técnicos considerou também que todos os cursos oferecidos foram bem divulgados pelo Sistema Gestor de Capacitação - SCGA, além de considerarem que o Curso de Iniciação não só foi útil para a Instituição, como também contribuiu para a melhoria do desempenho funcional, além de promover crescimento pessoal.

Uma unanimidade entre os respondentes considera que este Curso deveria ser obrigatório para os servidores recém admitidos no serviço público.

A entrevista realizada com a Diretora da Divisão de Capacitação e Afastamento para Formação - DCAF da UFSC teve o intuito de colher informações em relação ao tempo que a Instituição adota os cursos de iniciação, os critérios utilizados para sua definição, os instrumentos de avaliação para mensurar o grau de importância, como também verificar se há uma política consistente de gestão de pessoal na área de capacitação.

Conforme respondeu a Diretora da DCAF "foram criados alguns cargos de estrutura e questão comportamental, carreira do servidor e o seu papel dentro da UFSC, menos de serviços administrativos que é fruto de solicitação das chefias e direção das Unidades”.

O que se apurou de acordo com este depoimento é que os cursos de capacitação já existem desde a década de 70. A partir de 2007/2008 foi oferecido este curso de Iniciação, procurando preencher uma lacuna existente nas IFES, em possibilitar aos recém-contratados a oportunidade de conhecerem a Instituição em sua complexa estrutura, plano de carreira e política de desenvolvimento humano e social, e o seu papel do servidor técnicoadministrativo.

Apurou-se ainda que em todos os cursos são feitas avaliações de desempenho, através de formulário específico composto por quatro dimensões, ou seja: organização de curso/módulo, conteúdo do curso/módulo, atuação do ministrante, aprendizado e envolvimento dos participantes. No caso específico do curso de iniciação às atividades administrativas da UFSC, esta avaliação é feita através de uma dinâmica de grupo com a utilização deste mesmo formulário no sentido de reestruturar o curso, o que tem proporcionado mais uma oportunidade de trabalho em equipe e de se estabelecer um senso critico ao processo.

Com relação à política para gestão de pessoal, atualmente é feito um levantamento das necessidades com o plano anual de capacitação e os programas de cursos, sempre levando em 
consideração a necessidade do servidor e da equipe de trabalho em consonância com o modelo de gestão de competência.

\section{CONSIDERAÇÕES FINAIS}

Esta pesquisa teve como objetivo averiguar o processo de ingresso dos servidores técnico-administrativos da UFSC, em relação ao curso de capacitação para iniciantes oferecido pelo Sistema Gestor de Capacitação SGCA/UFSC, conceituado de acordo com a Portaria Normativa $\mathrm{n}^{\mathrm{o}}$. 017/GR/2008 como atividade de aprendizagem que procura desenvolver as competências institucionais por meio das competências individuais dos servidores.

Comparando o conteúdo programático do Curso de Iniciação às atividades técnicoadministrativas da UFSC, com as respostas fornecidas ao questionário aplicado aos 57 servidores respondentes, constatou-se que os objetivos enumerados no art. $7^{\circ}$, $\S$ Único, I, da Lei $n^{\circ} .5 .825 / 2006$, que diz respeito especificamente ao conhecimento da função do Estado, à missão da IFE e a conduta do servidor público e sua integração no ambiente institucional, têm sido atendidos.

Foi constatado também, que o perfil dos servidores técnico-administrativos melhorou consideravelmente nestes últimos anos, porquanto são servidores mais maduros e com maior formação acadêmica.

O progresso na área de gestão de pessoas, mais especificamente na área de treinamento e capacitação nas Universidades, tem avançado devido às necessidades impostas pelas mudanças do Estado e da Sociedade.

A Lei $n^{\circ} .11 .091 / 2005$ trouxe inovações para a área de gestão de pessoas, mas os avanços ainda são insuficientes. Não há autonomia, porquanto as Universidades são regidas por Leis Federais, e estas é que determinam as políticas de Recursos Humanos nas Universidades.

O processo de treinamento nas Instituições deve ser muito bem estruturado, de modo que possa abranger, além de questões comportamentais e estruturais da Instituição, a necessidade de conhecimento/informação necessários à execução das atividades exercidas pelo servidor.

Esta carência de capacitação em atividades práticas administrativas pode ser reconhecida nas ações da própria Universidade, uma vez que elabora seus Editais de Concursos para a Contratação de Servidores Técnico-Administrativos, solicitando como pré-requisito um ano 
de experiência profissional na área.

Sugere-se em vista disso, uma política de capacitação onde as fases do processo de treinamento sejam implantadas na sua totalidade, pois conforme defende Rizzati (1995), com o instrumento adequado é possível trazer contribuições importantes às Universidades, principalmente na identificação dos pontos fortes e fracos da Instituição, facilitando assim a implementação das mudanças necessárias para a melhoria do trabalho e para a satisfação dos seus servidores, porém para isso, necessário se faz ter indicadores, componentes e as categorias adequadas para fazer o estudo do clima em Universidades.

\section{REFERÊNCIA DAS FONTES CITADAS}

BRASIL. Decreto $n^{\circ}$. 5.825, de 29 de junho de 2006. Disponível em: http://www.planalto.gov.br/ccivil_03/_ato2004-2006/2005/lei/111091.htm

. Lei $\mathrm{n}^{\mathrm{o}}$. 11.091, de 12 de janeiro de 2005. Disponível em: http://www.planalto.gov.br/ccivil_03/_ato2004-2006/2005/lei/111091.htm.

CAMPOS, I. F.; VERNI, M. Gestão Universitária: Uma Analogia do Ponto de Vista de Dinossauros, Gazelas e Tigres em Três Instituições de Ensino Superior Privado. VI Colóquio Internacional Sobre Gestão Universitária na América do Sul, Blumenau-SC, 2006.

CEFET/RJ, Centro Federal de Educação Tecnológica Celso Suckow da Fonseca (2005) Plano de Desenvolvimento Institucional - PDI 2005/2009. Rio de Janeiro:CEFET/RJ.

CORADINI, Marlei Teresinha. Política de incentivo à capacitação para os servidores técnico-administrativos em educação da UFSM/RS. Artigo publicado na Revista ADMpg Gestão Estratégica, v. 4, n. 1, 2011. Disponível em:

http://www.admpg.com.br/revista2011/artigos/7.pdf.

CRISÓSTOMO, Israel. A importância das pessoas nas organizações. Disponível em: http://www.administradores.com.br/informe-se/artigos/a-importancia-das-pessoas-nasorganizacoes/22510/

DUTRA, J. C. Gestão de Pessoas. Modelo, Processos, Tendências e

Perspectivas. $1^{\mathrm{a}}$ Ed, São Paulo, 2002.

GIL, Antônio Carlos. Como Elaborar um Projeto de Pesquisa. $3^{\text {a }}$ ed., São Paulo, Atlas. 1994.

Métodos e Técnicas de Pesquisa Social. $5^{\text {a }}$ ed. São Paulo: Atlas, 1999.

GRILLO, Antônio Niccoló. Gestão de pessoas: princípios que mudam a administração 
universitária. Florianópolis: UFSC, 2001.

LÜCK, H. et al. A Escola Participativa: o trabalho do gestor escolar. 5. ed. Rio de Janeiro: DP\&A, 2001. 166 p.

MAGALHÃES, Elenice Maria de, et al. A política de treinamento dos servidores técnicoadministrativos da Universidade Federal de Viçosa (UFV) na percepção dos treinados e dos dirigentes da instituição. Artigo publicado em: rap — Rio de Janeiro 44(1):55-86, JAN./FEV. 2010. Disponível em: http://www.scielo.br/pdf/rap/v44n1/v44n1a04.pdf. Acesso em: 28 jul.2011

MARQUES, S. M. Processo de capacitação continuada: o caso da Universidade Federal de Juiz de Fora. 2002. Dissertação (Programa de Pós Graduação em Engenharia de Produção). UFSC, Florianópolis. Disponível em: http://teses.eps.ufsc.br/Resumo. Acesso em: 28 jul. 2011.

MENEGASSO, Maria Ester, SALM, José Francisco. A educação continuada e (a) capacitação gerencial: discussão de uma experiência. Revista de ciências da administração, Florianópolis, UFSC, ano 3, n. 5, mar./2001.

MOSCOVICI, Fela. Desenvolvimento interpessoal : treinamento em grupo. 13. ed. rev. e ampl. - Rio de Janeiro (RJ): Jose Olympio, 2003. 276p.

OLIVIER, Marilene. Planejamento estratégico e gestão de recursos humanos: casos e descasos nas universidades federais. In: Encontro Nacional dos Programas de Pós-Graduação em Administração, 2001. Campinas/SP. ENANPAD, 2001.

PACHECO, R.S. Política de recursos humanos para a reforma gerencial. Revista do Serviço Público, v. 53, n. 4, out/dez. 2002.

PEREIRA, J. C. R. Análise de Dados Qualitativos: estratégias metodológicas para as ciências da saúde, humanas e sociais. 3. ed. São Paulo: EDUSP, 2001. 144 p.

RIZZATTI, G. Análise de fatores significativos do clima organizacional da UFSC: contribuição para implantação do programa de qualidade. Florianópolis. Dissertação (mestrado). Departamento de Engenharia de Produção e Sistemas. UFSC, 1995.

ROBBINS, Stephen P. Comportamento Organizacional (Tradução técnica: Reynaldo Marcondes). 9 ed. São Paulo: Prentice Hall, 2002. 524 p.

SOUZA, Irineu Manoel de. Gestão das Universidades Brasileiras: uma abordagem fundamentada na gestão do conhecimento. 2009. $01 \mathrm{v}$. Tese (Doutorado) - Curso de Engenharia do Conhecimento, Departamento de Engenharia e Gestão do Conhecimento, Universidade Federal de Santa Catarina, Florianópolis, 2009.

TACHIZAWA, Taleshuy; FERREIRA, Victor Cláudio Paradela; FORTUNA, Antônio 
Alfredo Mello. Gestão com pessoas: uma abordagem aplicada às estratégias de negócios. 2. Ed. Rio de Janeiro: FGV, 2001.

UNIVERSIDADE FEDERAL DE SANTA CATARINA. Portaria Normativa $\mathrm{n}^{\circ}$. 017/GR/2008. Disponível em: http://www.sgca.ufsc.br/web/help portaria.jsp. Acesso em: 08 ago.2011.

VERGARA, Sylvia Constant. Projetos e Relatórios de Pesquisa em Administração. São Paulo: Atlas, 2005. 


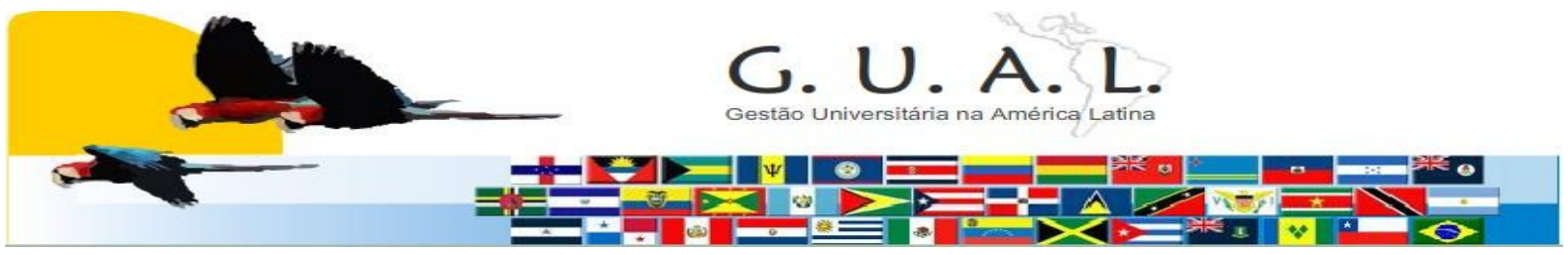

ISSN 1983-4535

\title{
EVALUATION OF THE PROCESS OF ENTRANCE OFTHE TECHNICIAN-ADMINISTRATIVE SERVANTS OFSANTA CATARINA'S FEDERAL UNIVERSITY - UFSC
}

\author{
Adão de Oliveira Filho, Specialist \\ Universidade Federal de Santa Catarina - UFSC \\ adao12br@yahoo.com.br \\ Daniela Quadros, Specialist \\ Universidade Federal de Santa Catarina - UFSC \\ danielaquadros@yahoo.com.br \\ Rogério da Silva Nunes, Doctor \\ Universidade Federal de Santa Catarina - UFSC \\ rogerionunes@cse.ufsc.br
}

\begin{abstract}
The article has the objective of evaluating the process of entrance of the technicianadministrative servants of the Federal University of Santa Catarina - UFSC, in relation to thecourse of Initiation the Administrative Activities since his/her beginning in 2008. Through astudy of case of descriptive and qualitative nature with the recentlycontracted servants thatparticipated in this course in the period from 2008 to 2011 and interview with the Director ofthe Division of Training and Removal for Formation of the Prórectory of Human and SocialDevelopment of UFSC - DCAF/PRDHS, was ended that the results are positive in therequirement regarding personal growth and knowledge of the Institution, but they leave towant in what tells respect the a politics of training administration in relation to the recentlycontracted ones, when it doesn't include subjects and inherent activities to the administrativeroutine, in agreement with the technicians' request and of the leaderships. In spite of therebeing a politics of personnel's administration in the area of aligned training to the offeredcourses, the process still lacks a larger structure, once no there is an evaluation about thepractical application of the courses in the institutional atmosphere.
\end{abstract}

Keywords: Training of servants. Politics of people's administration. Human resources. 